This item was submitted to Loughborough's Research Repository by the author.

Items in Figshare are protected by copyright, with all rights reserved, unless otherwise indicated.

\title{
Electromagnetic bandgap antennas and components for microwave and (Sub)millimeter wave applications
}

PLEASE CITE THE PUBLISHED VERSION

http://dx.doi.org/10.1109/TAP.2003.817566

PUBLISHER

(C) Institute of Electrical and Electronics Engineers (IEEE)

VERSION

VoR (Version of Record)

LICENCE

CC BY-NC-ND 4.0

REPOSITORY RECORD

de Maagt, Peter, Ramon Gonzalo, J.C. Vardaxoglou, and Jean-Marc Baracco. 2019. "Electromagnetic Bandgap Antennas and Components for Microwave and (sub)millimeter Wave Applications". figshare. https://hdl.handle.net/2134/9422. 
This item was submitted to Loughborough's Institutional Repository (https://dspace.lboro.ac.uk/) by the author and is made available under the following Creative Commons Licence conditions.

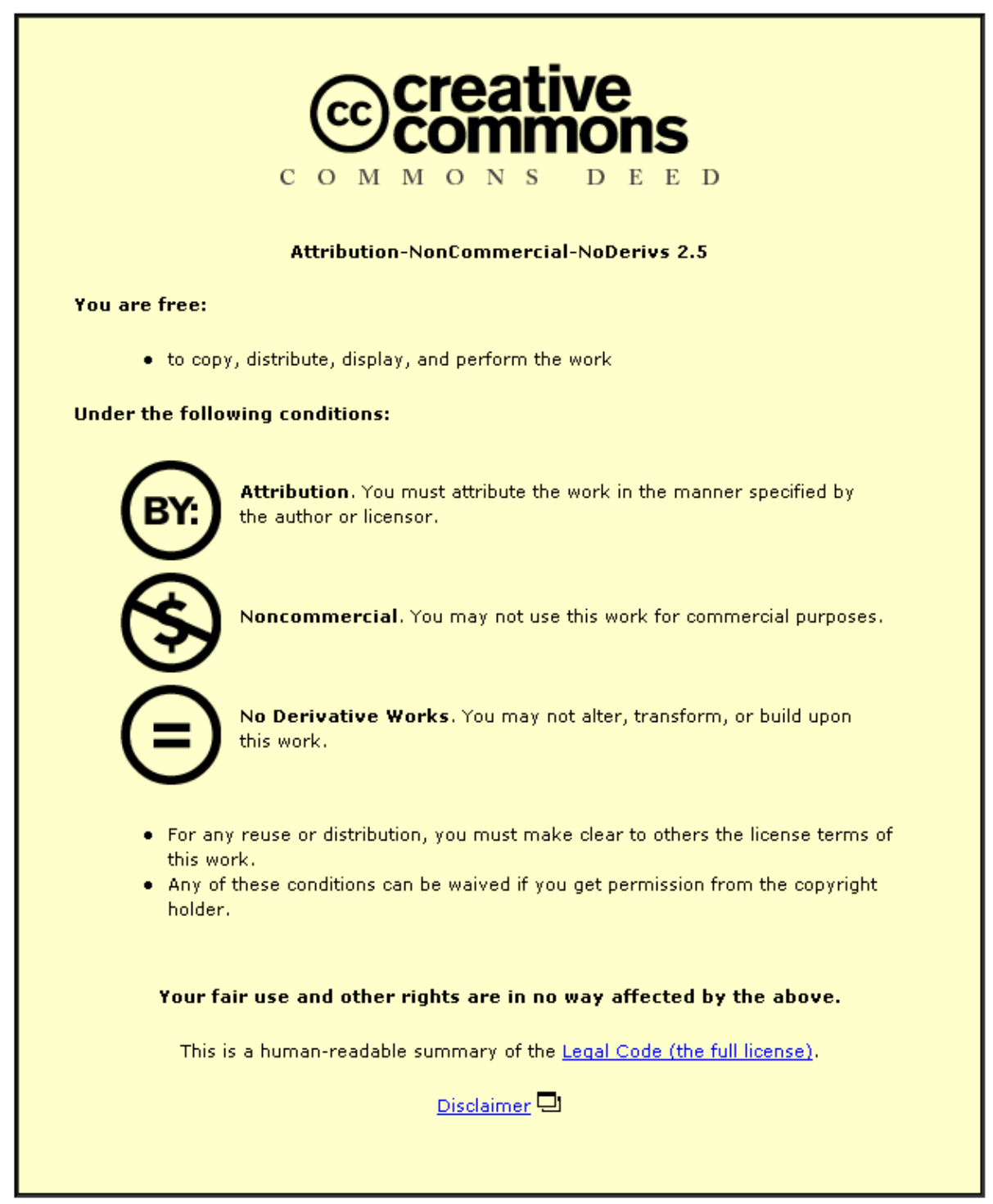

For the full text of this licence, please go to: http://creativecommons.org/licenses/by-nc-nd/2.5/ 


\title{
Electromagnetic Bandgap Antennas and Components for Microwave and (Sub)Millimeter Wave Applications
}

\author{
Peter de Maagt, Senior Member, IEEE, Ramón Gonzalo, Member, IEEE, Yiannis C. Vardaxoglou, Member, IEEE, \\ and Jean-Marc Baracco
}

\begin{abstract}
This paper reviews the primary application areas of electromagnetic bandgap (EBG) technology at microwave and (sub)millimeter wave frequencies. Examples of EBG configurations in the microwave region include array antennas, high precision GPS, mobile telephony, wearable antennas and diplexing antennas. In the submillimeter wave region a $500 \mathrm{GHz}$ dipole configuration and a novel heterodyne mixer is shown for the first time. Some emphasis is also placed on EBG waveguides and filters. As most fundamental components will be available in EBG technology, a fully integrated receiver could be developed in order to take full advantage of this technology. True integration of passive and active components can now begin to materialise using EBG technology.
\end{abstract}

Index Terms-Antenna, electromagnetic bandgap technology, microwave and (sub)millimeter components and devices.

\section{INTRODUCTION}

$\mathbf{M}$ ICROWAVE engineers are familiar with the concept of electromagnetic waves interacting with (singly or doubly) periodic structures. Periodic structures in both closed metallic or open waveguides have been used for many years, for example, in filters and travelling-wave tubes. Planar versions of these can be found in the form of frequency selective surfaces (FSS) and phased array antennas.

In the late 1980s, a fully three-dimensional (3-D) periodic structure, working at microwave frequencies, was realized by Yablonovitch [1] and his co-workers by mechanically drilling holes into a block of dielectric material. This so-called material, "Yablonovite," prevents the propagation of microwave radiation in any 3-D spatial direction whereas the material is transparent in its solid form at these wavelengths.

These artificially engineered materials are generically known as photonic bandgap (PBG) materials or photonic crystals. Although "photonic" refers to light, the principle of "bandgap"

Manuscript received December 5, 2002; revised March 20, 2003.

P. de Maagt is with the Electromagnetics Division, European Space Research and Technology Centre (ESTEC), European Space Agency (ESA), 2200 AG Noordwijk, The Netherlands (e-mail: Peter.de.Maagt@esa.int).

R. Gonzalo is with the Electrical and Electronic Engineering Department, Universidad Publica de Navarra, Campus Arrosadia, E-31006, Pamplona, Navarra, Spain.

Y. C. Vardaxoglou is with the Department of Electronic and Electrical Engineering, Loughborough University, Loughborough, Leicestershire, LE11 3TU, U.K.

J.-M. Baracco is with the MARDEL, 06140 Vence, France

Digital Object Identifier 10.1109/TAP.2003.817566 applies to electromagnetic waves of all wavelengths. Consequently, there is a controversy in the microwave community about the use of the term "photonic" [2], and the name electromagnetic bandgap (EBG) material or electromagnetic crystal is being proposed.

EBG materials are presently one of the most rapidly advancing sectors in the electromagnetic arena. They allow us to manipulate the propagation of electromagnetic waves to an extent that was previously not possible. The rapid advances in both theory and experiment together with substantial technological potential have driven the development of EBG technology. Emphasis is now placed on finding tangible applications combined with detailed modeling. Owing to the tremendous potential of EBG structures there is a plethora of applications in which they can be used. New start-up companies have been founded solely to exploit the commercial potential of this technology.

Communications services are one pertinent example of an increasingly important area. There has been a significant increase in demand for high-speed data services for voice and multimedia applications, particularly for accessing the Internet and the fixed and mobile services. As a result, broadband microwave wireless access has emerged.

Technically, these applications look for new frequency allocations with higher operational frequencies around 30, 40, and $60 \mathrm{GHz}$ for point-to-point, point-to-multipoint and high density fixed services, respectively.

Furthermore, technology in the submillimeter wave region of the electromagnetic spectrum is currently experiencing an explosive growth. The growth is fuelled in part by the need for faster signal processing and communications, high-resolution spectroscopy, atmospheric and astrophysical remote sensing and medical imaging for cancer detection. The increased atmospheric absorption and specific molecular resonances observed over this range of frequencies gives rise to applications in secure ultra-high bandwidth communication networks.

EBG technology offers promising alternatives to try and overcome the limitations of the current technology and it is envisaged that many new structures will evolve. EBG technology can represent a major breakthrough with respect to the current planar approaches, mainly due to their ability to guide and efficiently control electromagnetic waves. In order to get the most of this technology, a fully integrated receiver or emitter system 
should be developed in which all the components are designed using EBG technology. The first step in order to achieve this goal is the design of the individual components.

This paper starts with a discussion on basic EBG performance and computational tools for analysis and design. It subsequently shows some applications in the microwave and submillimeter wave frequency range. Several existing EBG antennas, waveguiding and filter configurations are highlighted. Emphasis is also placed on tunability of devices.

Owing to the newness of the subject area and associated devices, novel modeling tools and testing procedures have been successfully developed. A large part of the research at microwave frequencies is already applications driven, while the developments of submillimeter wave systems remain technologically more demanding. The simultaneous developments at these two frequency ranges provide verification of scalability in design and provide essential insight into any possible optical applications of such devices.

Due to the large number of groups that have started working in this field, it is impossible to incorporate a complete list of original and pertinent researches. There are many books, special journal issues and journal articles written in this area and the interested reader should consult them for finding more details on the many novel configurations that exist.

\section{NumericAl Modeling OF EBG CRYSTALS}

As in any novel technological field, on occasion a cut and try method was applied initially because of the lack of reliable prediction methods. The theoretical description of electromagnetic waves in electromagnetic band gap crystals involves the exact solution of Maxwell's equations in a periodic medium. Over the past few years, several techniques have emerged which allow us to predict the performance of EBGs providing useful prefabrication data.

The first models were based on scalar theory, but, it was soon discovered that this did not provide the accuracy required; consequent models are based on the full vectorial Maxwell's equations. While other techniques exist (Order-N [3], FDTD, etc), two techniques are used very frequently:

\section{A. Plane Wave Expansion or Spherical Wave Expansion}

This method starts with the Maxwell's equations in a generalized eigenvalue form. The plane wave expansion allows this set of equations to be solved by converting them into a Hermitian eigenvalue problem [4] and many commercial packages exist to aid in their solution. Because the plane wave method is easy to understand and is computationally very straightforward to implement, it became the first method to find widespread use. As many plane waves are usually required in order to obtain good convergence this can limit the use of the method for treatment of more complicated crystals. Several means have been proposed to improve the convergence of the plane-wave expansion [5]. Spherical waves may be used instead of plane waves as a basis set if the electromagnetic crystal is composed of spherical or cylindrical parts. This method is called the spherical-wave expansion method of the vector KRR (Koringa-Kohn-Rostker) method [6].

\section{B. Transfer Matrix Method}

At a fixed frequency, the equations are solved in the plane perpendicular to the crystal surface normal for a given propagation depth through the crystal (boundary value problem). The field is then transferred throughout the crystal by successively applying Maxwell's equations to obtain the scattering matrix for a single layer of crystal [7]. By cascading the scattering matrix for each layer, the transmission and reflection coefficients can be propagated down through layers by successive matrix multiplication

These methods are able to reproduce experimental results well and both allow that the physics of some specific properties of electromagnetic crystals to be intuitively understood. The initial results from the plane-wave or spherical wave expansion method give the dispersion curves and allow modal visualization, while those of the transfer matrix method give the transmission and reflection coefficients of the crystal.

As soon as 3-D EBGs are analyzed both methods become computationally demanding, but in some cases one can still play simple but effective computational tricks that allow to treat some special 3-D structures [8].

\section{Applications of Microwave EBG Antennas}

A multitude of basic EBG applications exist especially within the microwave and low millimeter-wave region, for example in electronically scanned phased arrays, high precision GPS, Bluetooth, mobile telephony, wearable antennas, etc.

Electronically scanned phased arrays find their use in many applications. For example constellations of Low Earth orbit satellites can be used for high data-rate transmission for multimedia applications. These applications require scanned multibeam antennas with relatively wide bandwidth. Each beam is usually working in dual circular polarization. Most of these constellations will work at frequencies up to $30 \mathrm{GHz}$. The use of active phased array made in microstrip technology is then an attractive solution. However, the need for bandwidth and scanning increases the undesirable effects caused by surface waves. A very promising way to eradicate the problems created by surface waves, e.g., scan blindness, while at the same time improving performance, is to substitute standard dielectric substrates by EBG crystals [9], [10].

Another microwave application is high precision GPS. High precision GPS surveying can make measurements with subcentimeter accuracy levels. While software can greatly reduce multipath errors, extra precautions that can shield the antenna from unwanted multipath signals are needed to obtain these accuracies. Choke rings provide excellent electrical performance for GPS antennas, but they are usually very large, heavy and costly. Making use of the fact that metallo-dielectric EBG antennas can behave as artificial magnetic conductors, one can design EBG solutions in printed circuit technology [11].

As the world goes wireless, data and voice transmission are bound to become even more common. A lot of attention is now focused on Bluetooth [12], the first implementation of such systems in every day life. Moreover, for other applications like mobile-phones more attention is being paid to the shielding offered by the antenna and the potential health hazard. EBG technology may prove useful in mobile antenna handset designs [13] and 
reduce the radiation [specific absorption rate (SAR)] into the operator's hand and head. Note that all new mobile phones will display the SAR value of the handset.

Shielding is not only important to reduce health concern. It is also important in multipoint communications. For example, devices placed on the side of a laptop interact with the screen and the case, resulting in a lower bit-rate between two computers. Again electromagnetic crystals may play an important role in this area.

Future clothing may have a variety of consumer electronics built into the garments. Wearable antennas have received much interest recently due to the introduction of personal communication technology. Several applications of wearable antennas can be found, e.g., radio tagging and miniature remote cameras and eventually it may even help parents to pin point their child's position. Antennas play a paramount role in the optimal design of wearable or hand-held units used in these services. Clearly in designing these antennas, the electromagnetic interaction among the antenna, wearable unit and the human operator is an important factor to be considered. EBG technology has been proposed as a design solution [14].

Microwave filtering has also turned out to be an important area where electromagnetic crystals play an important role [15]. The broad stopband can be exploited to suppress spurious passbands always present in conventional microstrip filters. The sharp cutoff can also be used to improve the roll-off on a low-pass filter. Furthermore, combinations of conventional designs and electromagnetic crystals could lead to very compact structures.

The area of conventional waveguides is another field were hybrid solutions could play an important role. Rectangular waveguides with uniform field distributions are of great concern for applications in quasioptical power combining. A standard waveguide can be modified by placing of electromagnetic crystal on the two sidewalls of a waveguide [16], potentially creating a very efficient waveguiding structure.

Recently the coupled cavity waveguides (CCW) have attracted considerable attention. This concept is believed to enable bends in the waveguide with very low bend reflection loss [17].

\section{Microwave EBG Antennas AND COMPONENTS}

Several antenna configurations using EBG crystals have already been studied to mention but a few: dipole antennas [18], [19], slot antennas, [20], patch antennas [9], [21]-[24], bow-tie antennas [25], spiral and curl antennas [26]-[28], superstrate antennas or resonant cavity antennas [29]-[31], parabolic reflector antennas [32] and combinations of the above [33].

The patch antenna is a popular configuration at microwave frequencies as it is robust, conformable if required and inexpensive to manufacture. One limitation is the possible excitation of surface waves, which can result in poor efficiency, degradation of the radiation pattern, reduction in gain and increase in mutual coupling. Surface waves can become dominant if high dielectric constant substrates are used, such as the ones commonly used for MMIC RF circuitry, and also if the thickness of the substrate is increased in order to have a larger bandwidth. Furthermore,

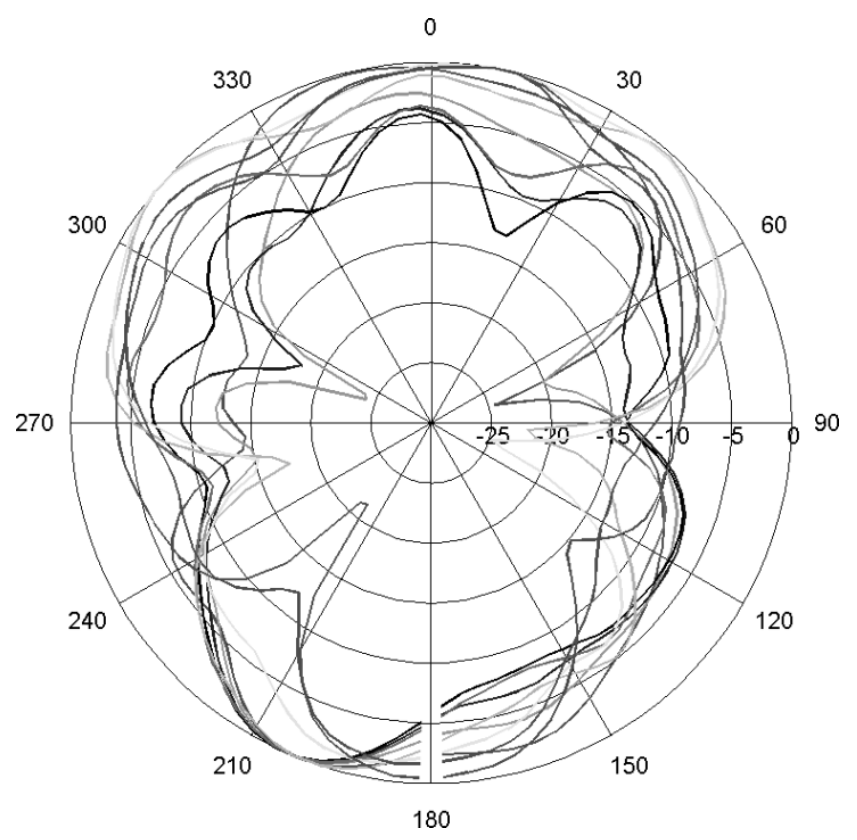

(a)

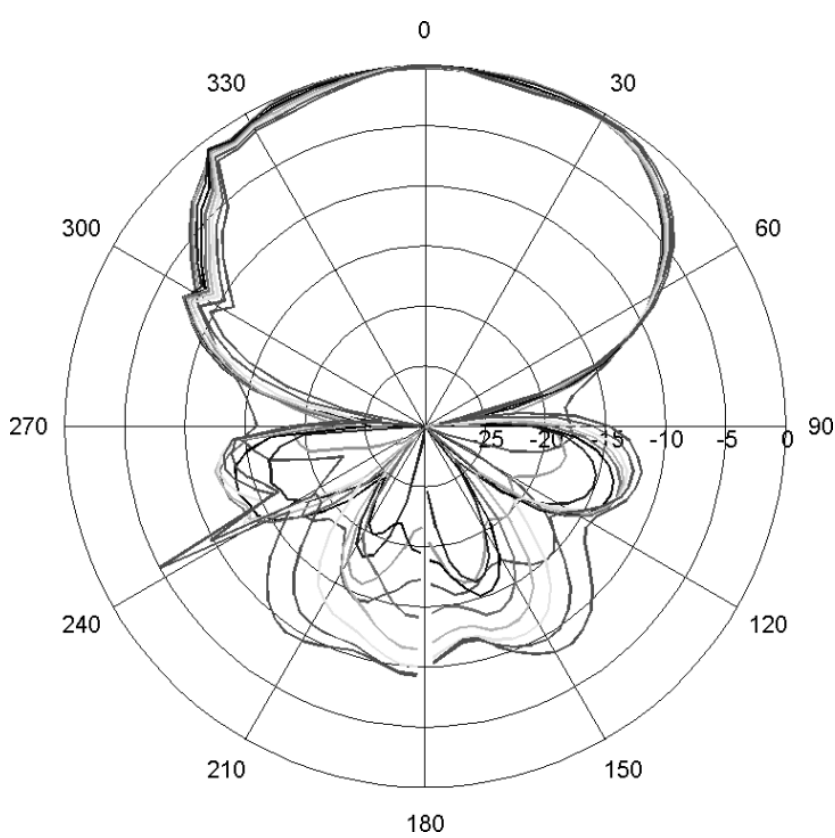

(b)

Fig. 1. Measured radiation patterns from 14 to $16 \mathrm{GHz}$ each $0.25 \mathrm{GHz}$ for the $\mathrm{H}$ plane for (a) the conventional patch antenna and for (b) the electromagnetic crystal substrate. Each line shows a different frequency value. Each division is $10 \mathrm{~dB}$.

if patches are to be used in an array configuration, the isolation between separate patches is generally believed not to be sufficient.

It has been demonstrated that EBG substrates for patch antennas significantly reduce the effect of surface waves as function of frequency [34] (see Fig. 1) and are able to provide relatively broadband frequency performance.

The superstrate and resonant cavity antennas differ slightly from the patch antennas that are working in the middle of the bandgap. Instead, they work at the edges of the bandgap (see 


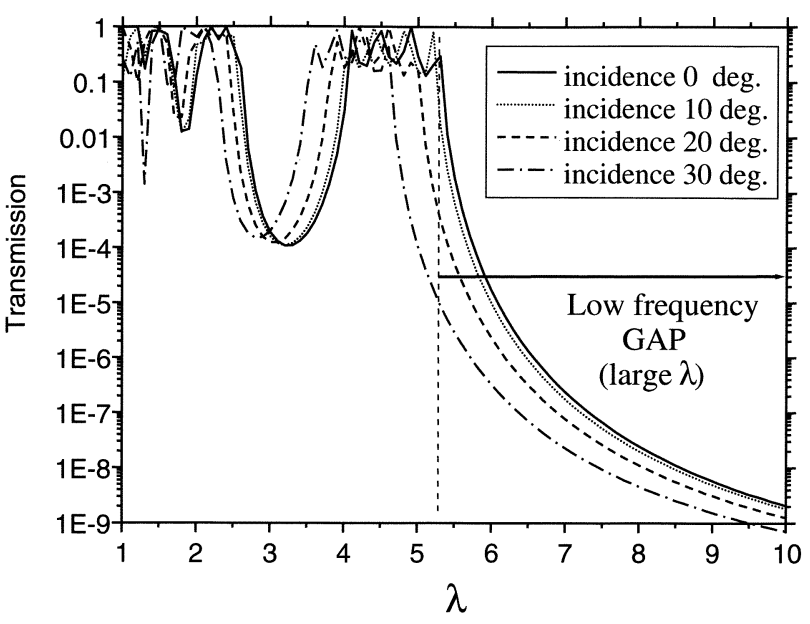

(a)

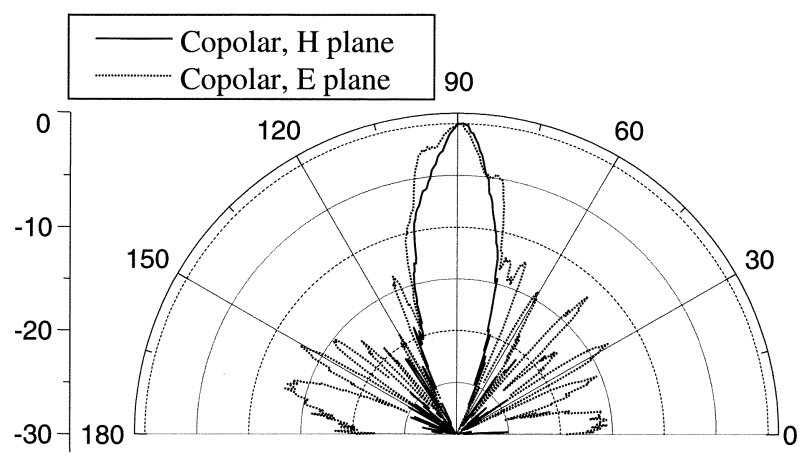

(b)

Fig. 2. (a) Transmission of a plane wave through a stack of five metallic grids. The vertical dashed line indicates the operational frequency. (b) Measured radiation pattern of a device consisting of six grids, placed on a ground plane, fed by a monopole in the center. Reproduced with the kind permission of Gerard Tayeb.

Fig. 2), making use of the fact that there is an angular dependence of the transmission curves. While full transmission is already achieved at normal incidence, significant attenuation still occurs for other angles [35]. The result is a highly directive radiation pattern, with good rotation pattern symmetry, but a rather narrowband performance.

In general, these are built using a ground plane underneath a feeding source (patch, slot, wire, ...), while a resonator cavity is formed by using a EBG material as a superstrate ([30] see Fig. 3).

Metallo Dielectric EBG antennas seem to do double action. They suppress surface currents, and they introduce in-phase image currents. The structure consists of a 2-D pattern of capacitive and inductive elements facilitating compact EBGs that operate at relatively low microwave frequencies.

Presently, there exist two main designs, the "high impedance ground plane" [36] which uses grounding pins to connect the 2-D pattern with a ground plane and the fully planar version "uniplanar compact photonic band-gap (UC-PBG)" [23].

Some simple 2-D arrays of conducting elements, have been used to improve the performance of patch antennas [37]. Fig. 4 shows an example of a hexagonal array of tripole elements around a patch and the resulting measured improvements in radiation pattern and return loss.

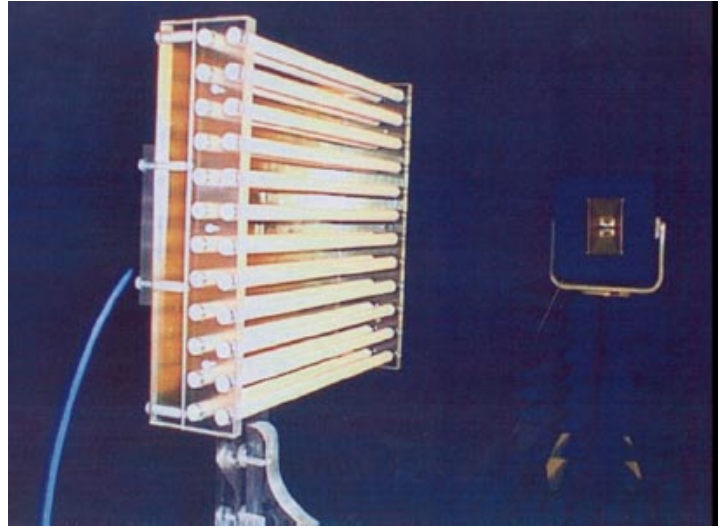

(a)

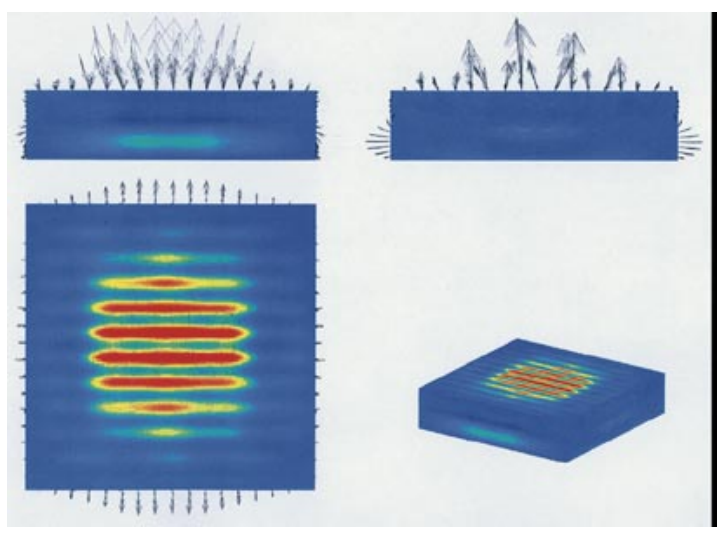

(b)

Fig. 3. (a) Resonant EBG antenna using a 2-D EBG as superstrate. (b) Poynting vector and electric field distribution on the 2-D EBG structure. Reproduced with the kind permission of Bernard Jecko.

The "reflection phase diagram" of Metallo Dielectric EBG structures gives information about how the structure reacts to a wave impinging on it. A characteristic feature of MD-EBGs is the existence of a frequency range over which an incident electromagnetic wave does not experience any $\pi$ phase reversal upon reflection. In this range the structure behaves as a perfect magnetic conductor (PMC).

It has been shown by measurements that for some structures the PMC behavior is rather insensitive to the angle of incidence. ([27] see Fig. 5)

The high-impedance ground plane has already been used for mobile telephone applications and good results have been reported [13]. The uniplanar compact photonic band-gap (UC-PBG) structure has already been applied in the design of microstrip diplexer patch antennas to enhance the isolation between Tx and Rx ports. It is demonstrated that some planar MEBG lattices are inherently anisotropic and their construction with different periods along two orthogonal directions exhibit different forbidden band-gap responses. The self-diplexing antenna on an anisotropic UC-PBG ground plane has demonstrated improved isolation, and this concept can lead to the development of direct integration of RF transceiver with planar antennas to realize on-chip antenna front-ends [38].

Very good performance has been obtained with these Metallo-Dielectric EBGs for next generation GPS applications 


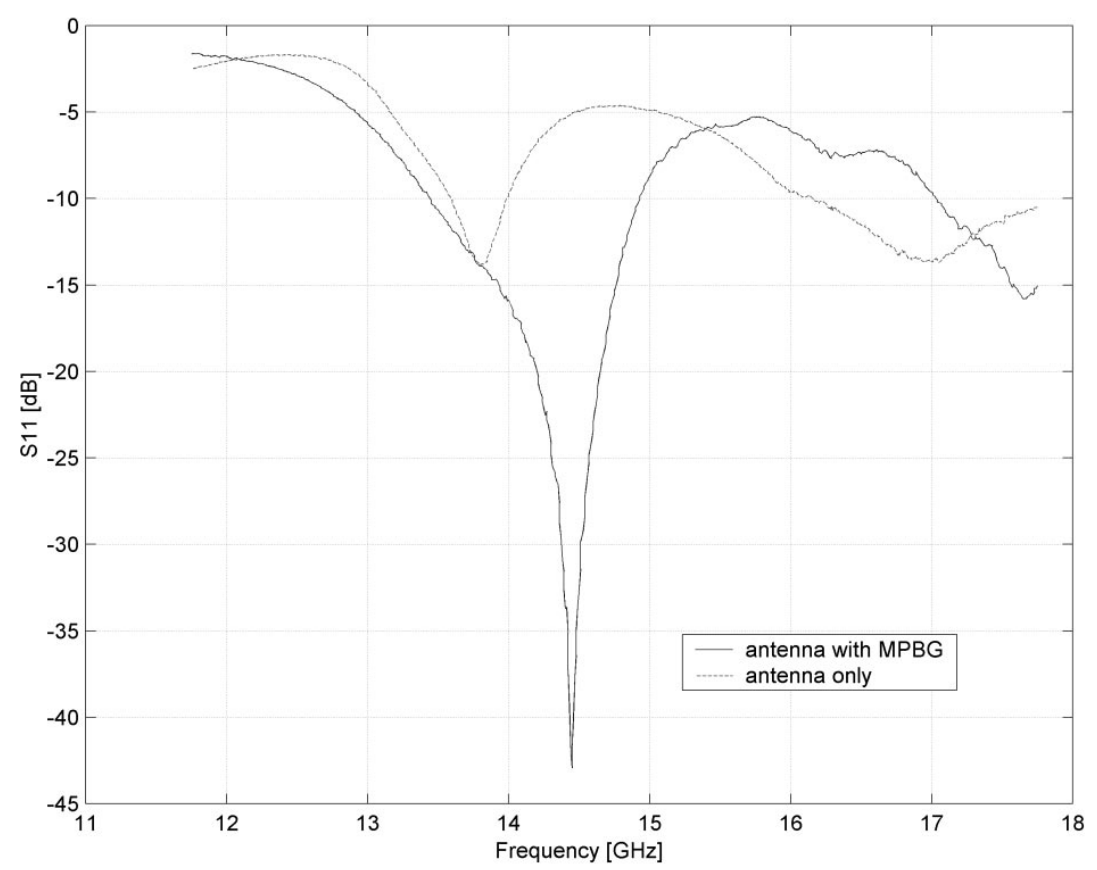

(a)

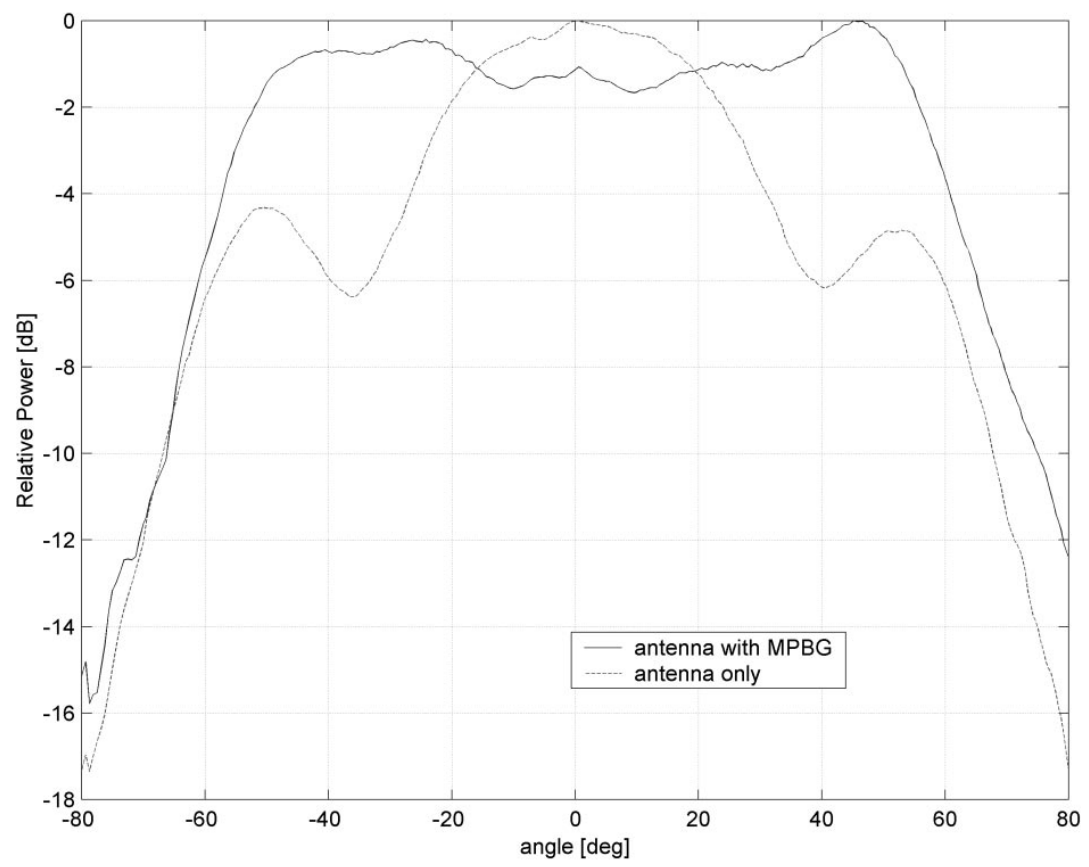

(b)

Fig. 4. (a) Return loss of patch antenna (see photo) with and without tripole M-EBG array. (b) H-plane radiation pattern measurements of patch antenna with and without tripole M-EBG array.

[11]. Fig. 6 shows a comparison between the performance of a chocked and a MD-EBG antenna. Not only the MD-EBG antenna reduces the weight by a factor of 10 , the height by a factor of four and is cheaper to manufacture, but it also outperforms the chocked horn by several decibels at the horizon.

\section{Tunable Electromagnetic Bandgap Antennas AND COMPONENTS}

A EBG component in an ideal concept would be fully dynamic, reconfigurable and multifunctional. Evidently, such a 


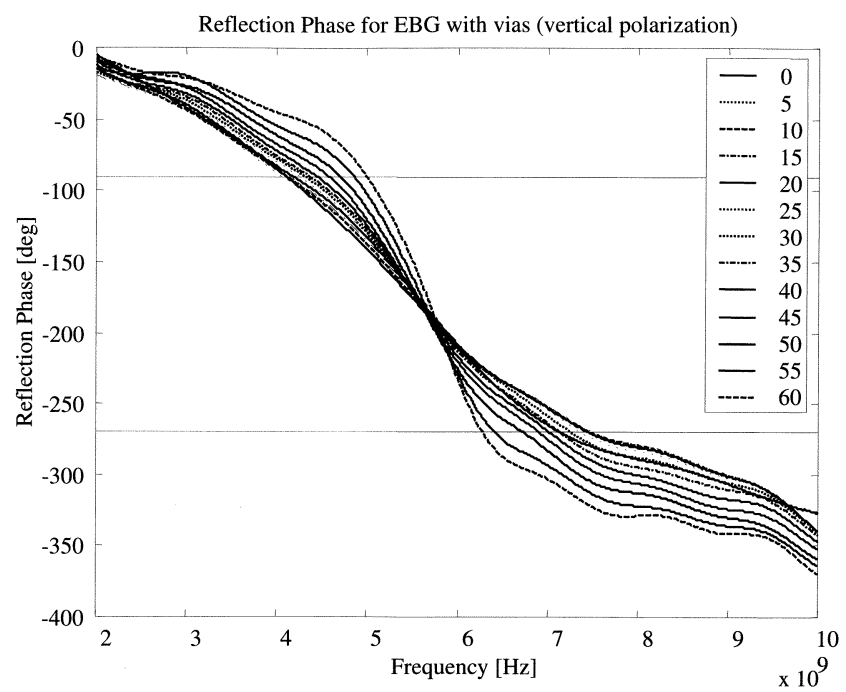

(a)

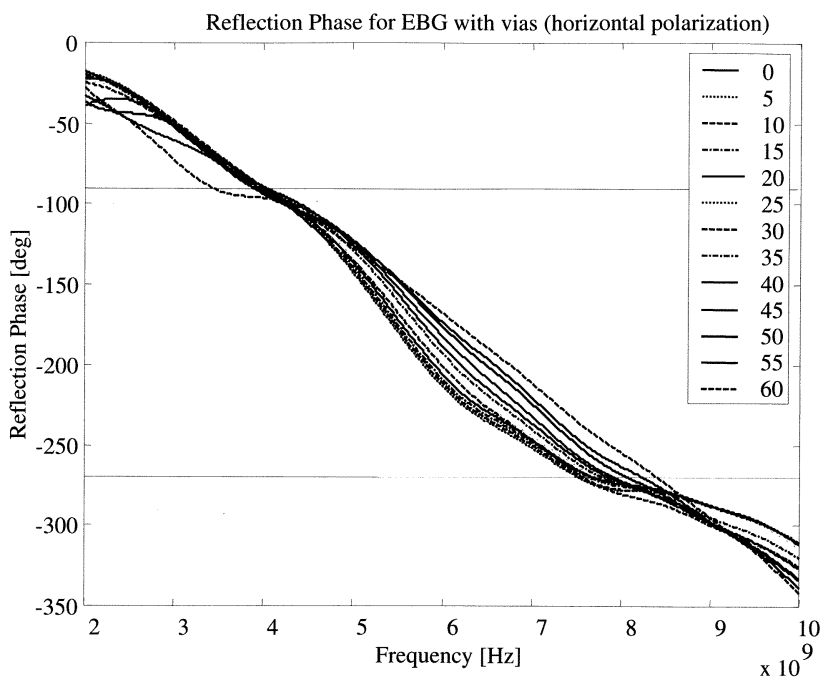

(b)

Fig. 5. Measured reflection phase versus angle of incidence for an MD-EBG design (see [27] with via's (a) vertical and (b) horizontal polarization).

concept is clearly visionary, but investigations into the basic tunability that electromagnetic crystals may provide is essential in evaluating their future role. To that end, a proof of concept and technological demonstration of tunability is essential.

As the properties of EBG components rely on the contrast between the dielectric constant of the materials involved, any variation of the dielectric constant of at least one of the involved materials, will lead to a sensitive tuning of the properties of the EBG component. Some alternatives exist to attain a tuning of the dielectric constant of the materials used for the EBG components:

- optically inducing a change of dielectric properties by photoexciting additional charge carriers;

- electrically inducing a change of dielectric properties by injecting additional charge carriers;

- micromechanically modifying the device geometry and/or the dielectric loading;

- electrically modifying the device geometry and/or the dielectric loading;

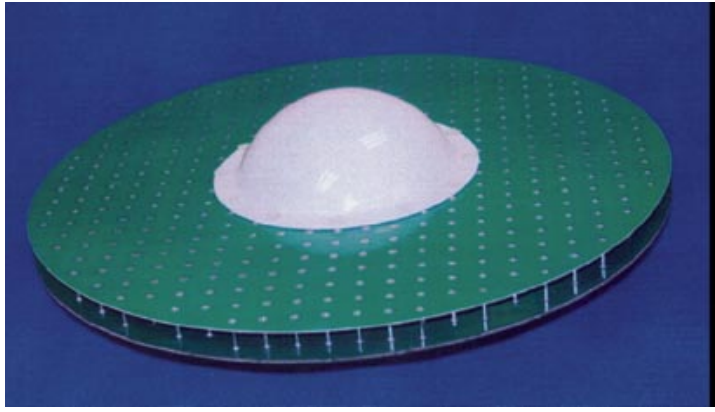

(a)

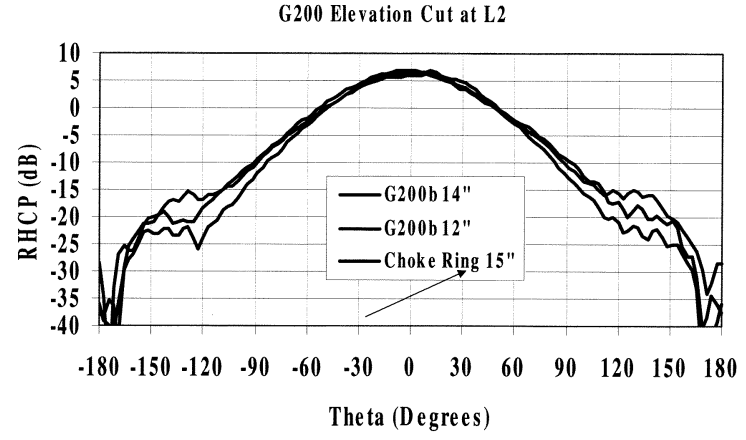

(b)

Fig. 6. (a) MD-EBG antenna for GPS applications. (b) measured pattern for a 12 and 14 in MD-EBG antenna, and a chocked version. Pattern roll-off of 14 in antenna better than the choke ring by 2 to $3 \mathrm{~dB}$ at horizon. Reproduced with the kind permission of Will Mc Kinzie.
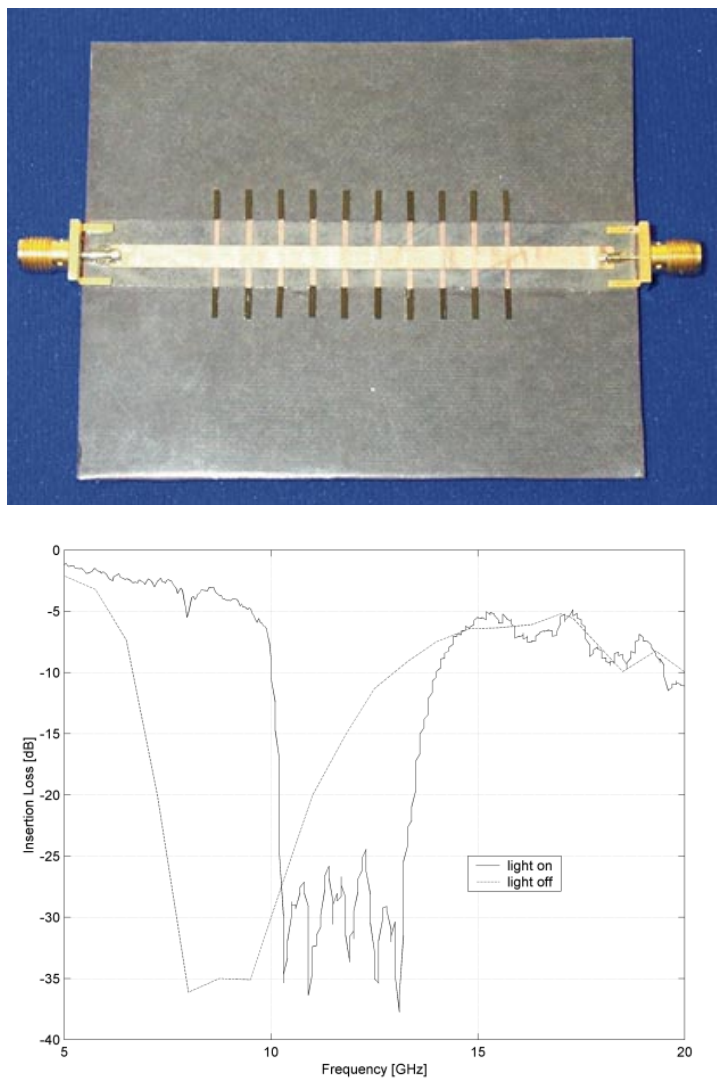

(b)

Fig. 7. (a) Photograph of a tunable EBG prototype High resistivity silicon strips can be seen at the dipole ends and (b) measured results of EBG tuning using an optical injection of carriers. 


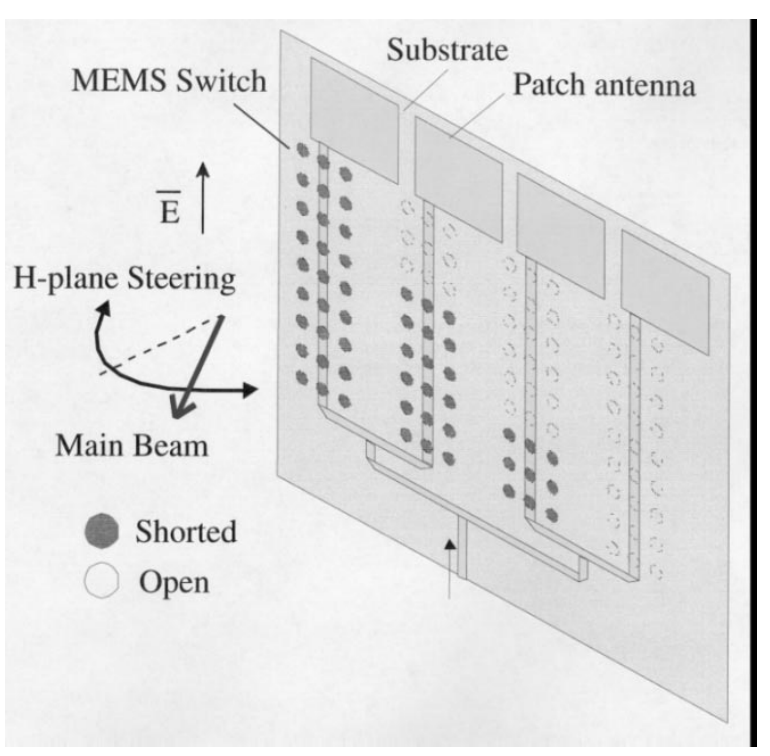

(a)

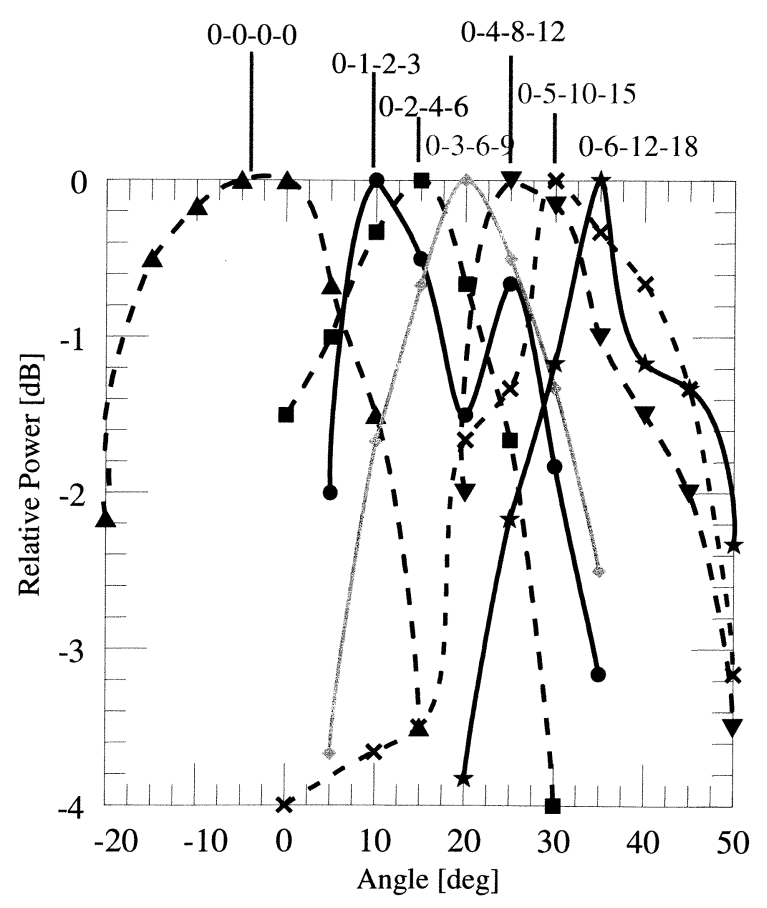

(b)

Fig. 8. (a) Four-element patch array with the EBG holes on the groundplane. Only nine EBG periods are shown here. (b) Measured beam patterns for the different ground-plane configurations. The array steers in increments of approximately $6^{\circ}$. Only the peaks of the steered pattern are shown. Reproduced with the kind permission of Jung-Chih Chiao.

The first two approaches are closely related, since the presence of additional charge carriers modifies the dielectric constant. Optically induced tunable devices are a useful approach for quickly being able to analyze the fundamental properties of charge carrier modulations to accomplish tunability in a device. Laser beams (both cw or pulsed) can be used to photoexcite charge carriers at certain locations inside the EBG components developed (switches, tunable filters, switchable directional couplers, etc.) ([39], see Fig. 7).

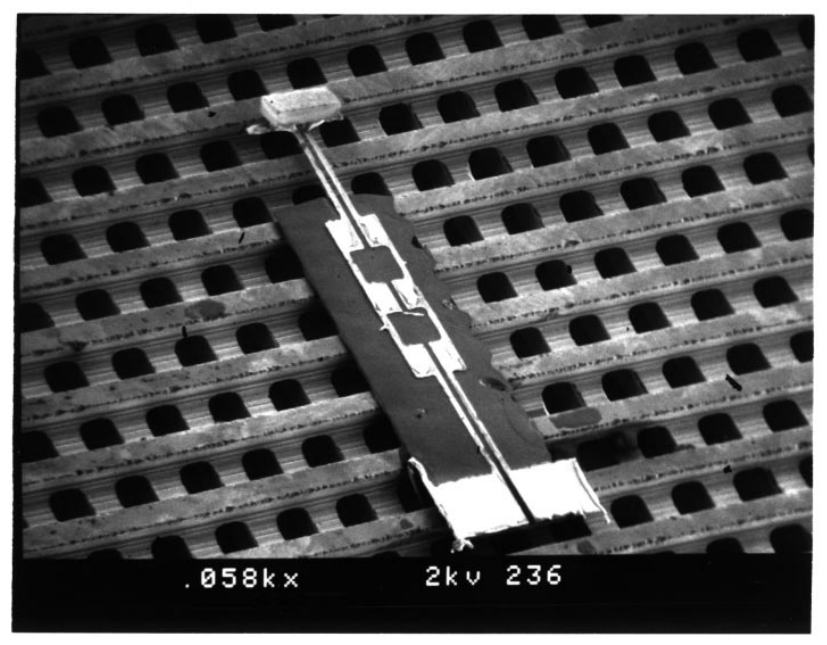

(a)

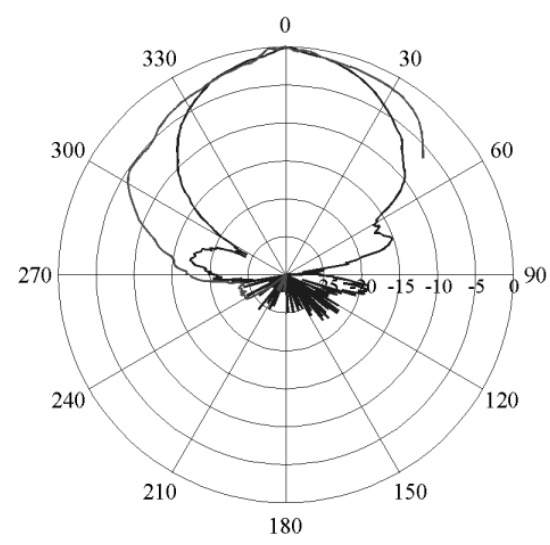

(b)

Fig. 9. $500 \mathrm{GHz}$ dipole antenna on top of woodpile (a) electron microscope photograph and (b) measured radiation pattern for the $\mathrm{E}$ and $\mathrm{H}$ planes.

The last two approaches are also closely related. The third method is based on micro electro mechanical systems (MEMS) fabrication technologies, where one can electrically modify the position of membranes and/or switches and modulate the local properties of the EBG components ([40], [41], see Fig. 8).

An example of the fourth category is given in [42], where PIN-diodes are inserted along the wires of a 2-D metallic structure.

\section{VI. (SUb)Millimeter WAVE ElECtRomagnetiC BANDGAP ANTENNAS}

A new generation of scientific space borne instruments, included in both Earth observation and scientific missions, is under consideration at millimeter and submillimeter wavelengths. As the frequency increases, a planar structure that integrates the antenna, mixer, local oscillator, and all peripheral circuitry onto one single substrate becomes an attractive option. While conceptually simple, in practice it is challenging to develop and test an integrated planar antenna on a semiconductor substrate that has good radiation efficiency and can be easily integrated with the active circuit. One of the problems 


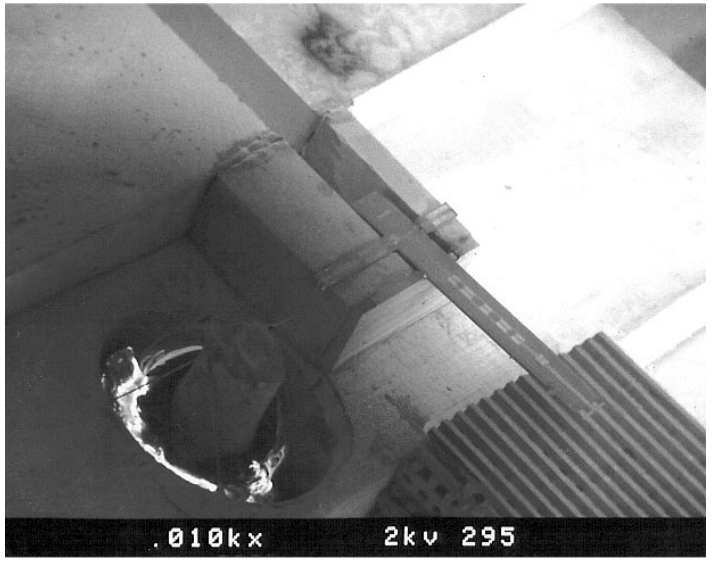

(a)

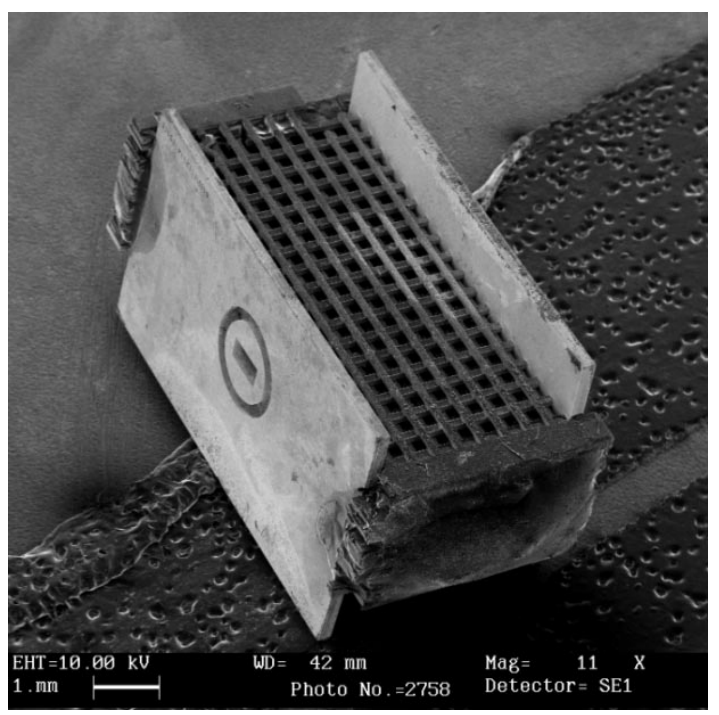

(b)

Fig. 10. (a) EBG heterodyne mixer at $250 \mathrm{GHz}$ and (b) submillimeter wave waveguide and transition to rectangular waveguide.

encountered, is that planar antennas on high dielectric constant substrates couple a significant fraction of the input power into substrate modes. Since these do not contribute to the primary radiation pattern, substrate mode coupling is generally considered as a loss mechanism. By removing the possible existence of substrate modes by using a EBG substrate the problem can be overcome, exemplifying the application of EBG materials. The radiation pattern of an integrated antenna system at $500 \mathrm{GHz}$ [18] is shown in Fig. 9. The EBG crystal used is the so-called layer-by-layer or woodpile structure [43].

A significant technological push has been achieved in this domain by the StarTiger concept from the European Space Agency. A submillimeter wave EBG mixer with good performance at room-temperature and several EBG components have been realized (see Fig. 10).

\section{EBG DEFECTS AND WAVEGUIDING}

An ideal EBG crystal is constructed by the infinite repetition of identical structural units in space. Considerable effort in theoretical, experimental and material fabrication research has predicted and demonstrated many of the properties of these ideal crystals. Introducing some disorder by placing a "defect unit" within an otherwise perfect EBG crystal can create localized transmission peaks within the forbidden band gap of the structure. Some of the works were based on a single-mode air waveguide created within in a square lattice of dielectric pillars. Even bends, couplers and add-drop multiplexers have been proposed in this technology [44], [45]. However, air waveguiding solutions in 2-D lack confinement in the third vertical direction. Furthermore, they require infinitely deep structures that can be readily analyzed but are more challenging to fabricate. A more pragmatic solution would be based on a dielectric waveguide and uses the inverse geometry, i.e., air holes in a dielectric host. Conversely, dielectric channel guidance does have the added benefit that guiding is maintained within the periodic plane by total internal reflection, which is not the case for guides made from air.

Recently an alternative to the linear defect waveguide has attracted considerable attention. This alternative makes use of a periodic chain of localized defects that have been either completely or partially in-filled. The introduction of several localized defects, within coupling distance of each other, opens up a mini-band of allowed transmission [17], [46]. Chains or cascades of localized defects form a mechanism for waveguiding, commonly referred to as coupled CCW. Experimental verification of 2-D CCWs has been performed in the microwave regime. It has frequently been assumed that bends can be introduced into the waveguide path by taking advantage of the crystal's inherent lattice symmetry without consequential bend reflection loss. However, it can theoretically be shown that the mini pass band created by coupled cavity waveguide bends may only reach $100 \%$ transmission for a strict set of criteria [17].

Another interesting application of defects is the terahertz local oscillator generation.

It is well known that a defect mode within a EBG is localized. This suggests that a high-Q and loss-less cavity for an electromagnetic wave can be realized, and that it is possible to make an efficient and compact oscillator. Using a nonlinear ZnTe material as the defect material it has been shown that it is possible to generate $\mathrm{THz}$ radiation [47].

\section{EBG FILTERS}

The use of EBG circuits for filter applications in planar microwave technology has been proposed in different ways. One approach is by means of a honeycomb-lattice of holes drilled in a microstrip substrate in order to achieve harmonic tuning in power amplifiers but the obtained rejection level and bandwidth are modest. To overcome the last problem, it has been proposed to realize the EBG by etching a 2-D structure of holes in the ground plane of the microstrip circuit [48].

Another way to produce compact designs is the "uniplanar compact EBG structure" where the slow-wave effect produced by a distributed LC 2-D structure allows a considerable size reduction in the circuit. A spurious-free band-pass filter and high-performance low-pass filter are obtained by using a coupled microstrip line in a slow-wave substrate [49]. 


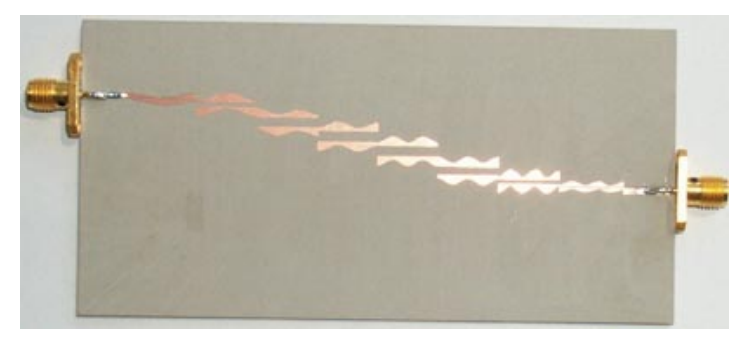

(a)

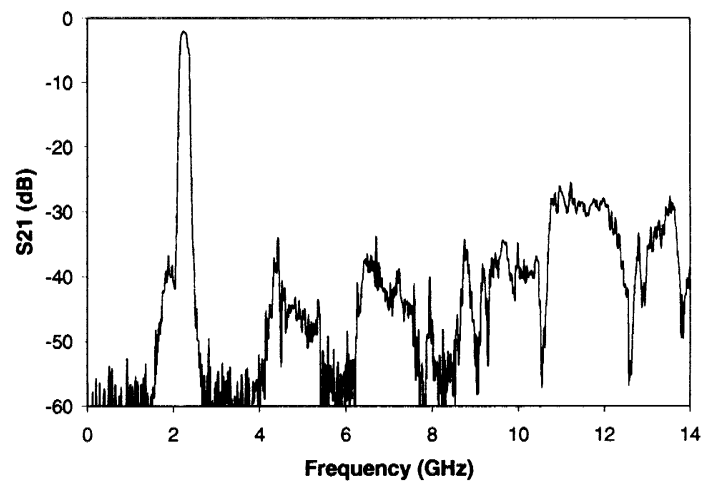

(b)

Fig. 11. (a) Picture of a Wiggly-line filter resulting after applying the strip width perturbation to the classical coupled-line order-7 Butterworth band-pass microstrip filter centered at $2.5 \mathrm{GHz}$ with a $10 \%$ fractional bandwidth. (b) Measured $\mathrm{S}_{21}$ parameter for the wiggly-line filter. Reproduced with the kind permission of Mario Sorolla.

The last approach consist of producing the EBG structure in the upper strip of the microstrip line to solve the fabrication problem of the defected ground plane structures. Even spurious free band pass filters are possible, maintaining the desired band response by using a continuous periodic strip modulation of the coupled lines width ([50] see Fig. 11).

\section{CONCLUSION}

Currently, there is a need for wide, multiband device functionality, and ideally multifunctional devices. As long as the market generates a technology pull, the development of novel components and subsystems will always be in demand. Ideally, these components and subsystems would be required to be dynamic, reconfigurable and multifunctional.

The technological potential of electromagnetic crystals for developing such novel components and subsystems offers a very promising alternative that could potentially overcome the limitations of current technology. EBG technology is a breakthrough, mainly due to their ability to guide and control efficiently electromagnetic waves.

In order to drive this technology toward the market place we will need to identify component feature(s) of EBG structures that give added value over and above current approaches. This paper has presented several applications where EBG technology could play a major role. Several antenna, waveguide and filter configurations are discussed in this paper. It is also shown that tunable EBG devices can be made. As many of the fundamental components do exist in EBG technology, the next step should be aiming toward the development of a complete system in the same technology.

\section{ACKNOWLEDGMENT}

The authors wish to thank all the people that contributed to this paper. In particular I. Ederra, and M. Sorrolla from Universidad Publica de Navarra, G. Tayeb from Institut Fresnel, B. Jecko from IRCOM, J-C. Chiao from University of Texas-Arlington, Y. Hao and C. Parini from Queen Mary University, P. Salonen from Tampere University of Technology, R. Ziolkowski from University of Arizona, W. McKinzie from Etenna, A. Reynolds from Nortel Networks, and R. Lee, R. Seager, A. Feresidis and A. Charaya from Loughborough University.

\section{REFERENCES}

[1] E. Yablonovitch, "Inhibited spontaneous emission in solid state physics and electronics," Phy. Rev. Lett., vol. 58, pp. 2059-2062, 1987.

[2] A. A. Oliner, "Periodic structures and photonic band-gap terminology: Historical perspectives," in Proc. 29th Eur. Microwave Conf., vol. 3, Munich, Germany, Oct. 1999, pp. 295-298.

[3] J. Arriaga, A. J. Ward, and J. B. Pendry, "Order-N photonic band structures for metals and other dispersive materials," Phys. Rev., vol. B59, pp. 1874-1877, 1999.

[4] G-i Kweon and N. M. Lawandy, "Quantum electrodynamics in photonic crystals," Opt. Communicat., pp. 388-411, July 1995.

[5] H. S. Sozuer and J. W. Haus, "Photonic bands: Convergence problems with the plane-wave method," Phys. Rev. B, Condens. Matter, vol. 45, no. 24, pp. 13962-13972, June 1992.

[6] N. Stefanou, V. Karathanos, and A. Modinos, "Scattering of electromagnetic waves by periodic structures," J. Phys. Condens. Matter, vol. 4, pp. 7389-7400, 1992

[7] P. M. Bell, J. B. Pendry, L. M. Moreno, and A. J. Ward, "A program for calculating photonic band structures and transmission coefficients of complex structures," Comput. Phys. Commun., vol. 85, pp. 307-322, 1995.

[8] A. L. Reynolds and J. M. Arnold, "Interleaving two-dimensional lattices to create three-dimensional photonic bandgap structures," in Proc. Inst. Elect. Eng. Optoelectronics, vol. 145, Dec. 1998, pp. 436-440.

[9] R. Gonzalo, P. de Maagt, and M. Sorolla, "Enhanced patch antenna performance by suppressing surface waves using photonic band-gap structures," IEEE Trans. Microwave Theory Tech., vol. 47, pp. 2131-2138, Nov. 1999.

[10] P. K. Kelly, L. Diaz, M. Piket-May, and L. Rumsey, "Scan blindness mitigation using photonic bandgap structure in phased arrays," in Proc. SPIE, vol. 3464, July 1998, pp. 239-248.

[11] R. Hurtado, W. Klimczak, W. E. McKinzie, and A. Humen, "Artificial magnetic conductor technology reduces weight and size for precision GPS antennas," presented at the Navigational National Technical Meeting, San Diego, CA, Jan 28-30, 2002.

[12] R. Remski, "Modeling photonic bandgap (PBG) structures using ansoft HFSS7 and optimetrics," in Ansoft International Roadshow (Lecture Series): Ansoft Corporation, 2000.

[13] R. F. J. Broas, D. F. Sievenpiper, and E. Yablonovitch, "A high-impedance ground plane applied to cellphone handset geometry," IEEE Trans. Microwave Theory Tech., vol. 49, pp. 1262-1265, July 2002.

[14] P. Salonen, M. Keskilammi, and L. Sydanheimo, "A low-cost 2.45 $\mathrm{GHz}$ photonic band-gap patch antenna for wearable systems," in Proc. 11th Int. Conf. Antennas and Propagation ICAP, Manchester, UK, Apr. 17-20, 2001, pp. 719-724.

[15] T. Lopetegi, M. A. G. Laso, R. Gonzalo, M. J. Erro, F. Falcone, D. Benito, M. J. Garde, P. de Maagt, and M. Sorolla, "Electromagnetic crystals in microstrip technology," Opt. and Quantum Elect., vol. 34, no. 1/3, pp. 279-295, Jan./Mar. 2002.

[16] F.-R. Yang, K.-P. Ma, Y. Qian, and T. Itoh, "A novel TEM waveguide using uniplanar compact photonic-bandgap (UC-PBG Structure)," IEEE Trans. Microwave Theory Tech., vol. 47, pp. 2092-2098, Nov. 1999.

[17] U. Peschel, A. Reynolds, B. Arredondo, F. Lederer, P. Roberts, T. Krauss, and P. de Maagt, "Transmission and reflection analysis of functional coupled cavity components," IEEE J. Quantum Electron., Special Issue: Photonic Crystal Structures Applicat., vol. 38, no. 7, pp. 830-837, June 2002. 
[18] R. Gonzalo, I. Ederra, C. Mann, and P. de Maagt, "Radiation properties of terahertz dipole antenna mounted on photonic crystal," Electron. Lett., vol. 37, no. 10, pp. 613-614, May 2001.

[19] M. M. Sigalas, R. Biswas, Q. Li, D. Crounch, W. Lleung, R. JacobsWoodbury, B. Lough, S. Nielsen, S. McCalmont, G. Tuttle, and K. M. Ho, "Dipole antennas on photonic band-gap crystals-Experiment and simulation," Microw. Opt. Tech. Lett., vol. 15, no. 3, pp. 153-158, June 1997.

[20] I. Ederra, J. J. Sanz, B. Martinez, R. Gonzalo, and P. de Maagt, "Slot antenna configuration using PBG technology," in Proc. Jina, vol. 2, Nice, France, Nov. 12-14, 2002, pp. 169-172.

[21] K. Agi, J. Malloy, E. Schamiloglu, M. Mojahedi, and E. Niver, "Integration of microstrip patch antenna with a two-dimensional photonic crystal substrate," Electromagn. Special Issue: Theory and Applications of Photonic Band-Gap Materials, vol. 19, no. 3, pp. 277-290, May-June 1999.

[22] J. S. Colburn and Y. Rahmat-Samii, "Patch antennas on externally perforated high dielectric constant substrates," IEEE Trans. Antennas Propagat., vol. 47, pp. 1785-1794, Dec. 1999.

[23] R. Coccioli, F. Yang, K. Ma, and T. Itoh, "Aperture-coupled patch antenna on UC-PBG substrate," IEEE Trans. Microwave Theory Tech., vol. 47, pp. 2123-2130, Nov. 1999.

[24] A. S. Andrenko, Y. Ikeda, and O. Ishida, "Application of PBG microstrip circuits for enhancing the performance of high-density substrate patch antennas," Microw. Opt. Tech. Lett., vol. 32, pp. 340-344, Mar. 2002.

[25] E. R. Brown, C. D. Parker, and E. Yablonovith, "Radiation properties of a planar antenna on a photonic-crystal substrate," J. Optic Soc. Amer. B, Opt. Phys., vol. 10, no. 2, pp. 404-407, Feb. 1993.

[26] T. H. Liu, W. X. Zhang, and M. Zhang, "A spiral antenna backed on photonic bandgap material," in Proc. ISAP 2000 on CD, Fukuoka, Japan, Aug. 21-25.

[27] J. M. Baracco and P. de Maagt, "Radiating element on a photonic bandgap structure for phased array applications," in Proc. Jina, vol. 2, Nice, France, Nov. 12-14, 2002, pp. 169-172.

[28] F. Yang and Y. Rahmat-Samii, "A low profile circularly polarized curl antenna over an electromagnetic bandgap (EBG) surface," Microw. Opt. Tech. Lett., vol. 31, no. 4, pp. 264-267, 2001.

[29] M. Thevenot, C. Cheype, A. Reineix, and B. Jecko, "Directive photonicbandgap antennas," IEEE Trans. Microwave Theory Tech., vol. 47, pp. 2115-2122, Nov. 1999

[30] C. Cheype, C. Serier, M. Thevenot, T. Monediere, A. Reineix, and B. Jecko, "An electromagnetic bandgap resonator antenna," IEEE Trans. Antennas Propagat., vol. 50, pp. 1285-1290, Sept. 2002.

[31] B. Temelkuran, E. Ozbay, J.-P. Kavanaugh, G. Tuttle, and K.-M. Ho, "Resonant cavity enhanced detectors embedded in photonic crystals," Appl. Phys. Lett., vol. 72, no. 19, pp. 2376-2378, May 1998.

[32] M. Thevenot, A. Reineix, and B. Jecko, "A dielectric photonic parabolic reflector," Microw. Opt. Tech. Lett., vol. 21, no. 6, pp. 411-414, June 1999.

[33] M. Qiu and S. He, "High-directivity patch antenna with both photonic bandgap substrate and photonic cover," Microw. Opt. Tech. Lett., vol. 30, no. 1, pp. 41-44, July 2001.

[34] R. Gonzalo, G. Nagore, I. Ederra, B. Martinez, H. Pellemans, P. H. Bolivar, and P. de Maagt, "Coupling between patch antennas on photonic crystals," in Proc. 24th ESTEC Antenna Workshop Innovative Periodic Antennas: Photonic Bandgap, Fractal and Frequency Selective Structures, Noordwijk, The Netherlands, May-June 30-1, 2001, pp. 17-22.

[35] S. Enoch, G. Tayeb, P. Sabouroux, N. Guérin, and P. Vincent, "A metamaterial for directive emission," Phys. Rev. Lett., vol. 89, p. 213902 , 2002.

[36] D. Sievenpiper, L. Zhang, R. F. J. Broas, N. G. Alexopolous, and E. Yablonovitch, "High-impedance high-impedance electromagnetic surfaces with a forbidden frequency band," IEEE Trans. Microwave Theory Tech., vol. 47, pp. 2059-2075, Nov. 1999.

[37] Y. R. Lee, A. Chauraya, D. S. Lockyer, and J. C. Vardaxoglou, "Dipole and tripole metallodielectric photonic bandgap (MPBG) structures for microwave filter and antenna applications," Proc. Inst. Elect. Eng. Optoelectron., vol. 127, no. 6, pp. 395-400, Dec. 2000.

[38] Y. Hao and C. Parini, "Isolation enhancement of PBG microstrip diplexer patch antenna," in Proc. 11th Int. Conf. Antennas and Propagation ICAP, Manchester, UK, Apr. 17-20, 2001, pp. 86-89.

[39] J. C. Vardaxoglou, D. S. Lockyer, Y. L. R. Lee, and A. Chauraya, "Photonic bandgap and bandpass characteristics from metallodielectric periodic arraystructures," in Proc. 24th ESTEC Antenna Workshop Innovative Periodic Antennas: Photonic Bandgap, Fractal and Frequency Selective Structures, Noordwijk, The Netherlands, May-June 30-1, 2001, pp. 213-217.
[40] M. J. Hill, R. W. Ziolkowski, and J. Papapolymerou, "A high-reconfigurable planar EBG cavity resonator," IEEE Microwave Wireless Components Lett., vol. 11, no. 6, pp. 255-257, June 2001.

[41] B. Elamaran, I-M. Chio, L.-Y. Chen, and H.-C. Chiao, "A beam-steerer using a reconfigurable PBG ground plane," in Proc. IEEE MTT-S Int. Microwave Symp., Boston, MA, June 11-16, 2000.

[42] A. Delustrac, F. Gadot, E. Akmansoy, and T. Brillat, "High-directivity planar antenna using controllable photonic bandgap material at microwave frequencies," App. Phys. Lett., vol. 78, p. 4196, 2002.

[43] R. Gonzalo, B. Martinez, C. Mann, H. Pellemans, P. H. Bolivar, and P. de Maagt, "A low cost fabrication technique for symmetrical and asymmetrical layer-by-layer photonic crystals at sub-millimeter wave frequencies," IEEE Trans. Microwave Theory Tech., vol. 10, pp. 2384-2393, Oct. 2002.

[44] S. Fan, P. R. Villeneuve, J. D. Joannopoulos, and H. A. Hauss, "Channel drop filters in photonic crystals," Opt. Express, vol. 3, no. 1, pp. 4-11, Apr. 1998.

[45] A. Mekis, J. C. Chen, I. Kurland, S. Fan, P. R. Villeneuve, and J. D. Joannopoulos, "High transmission through sharp bends in photonic crystal waveguides," Phys. Rev. Lett., vol. 77, no. 18, pp. 3787-3790, Oct. 1996.

[46] A. Reynolds, U. Peschel, F. Lederer, P. Roberts, T. Kraus, and P. de Maagt, "Coupled defects in photonic crystals," IEEE Trans. Microwave Theory Tech., vol. 49, no. 10, pp. 1860-1867, Oct. 2001.

[47] M. Tani, P. Gu, K. Sakai, H. Kitahara, M. Suenaga, and M. W. Takeda, "THz wave generation by difference frequency mixing in photonic crystal cavity," in Proc. 8th Int. Conf. Terahertz Electronics, Darmstadt, Germany, Sept. 28-29, 2000, pp. 301-304.

[48] V. Radisic, Y. Qian, R. Coccioli, and T. Itoh, "Novel 2-D photonic bandgap structure for microstrip lines," IEEE Microwave Guided Wave Lett., vol. 8, pp. 69-71, Feb. 1998.

[49] F. R. Yang, K. P. Ma, Y. Qian, and T. Itoh, "A uniplanar compact photonic bandgap (UC-PBG) structure and its applications for microwave circuits," IEEE Trans. Microwave Theory Tech., vol. 47, pp. 1509-1514, Aug. 1999.

[50] T. Lopetegi, M. A. G. Laso, J. Hernandez, M. Bacaicoa, D. Benito, M. J. Garde, M. Sorolla, and M. Guglielmi, "New microstrip "Wiggly - line" filters with spurious passband suppression," IEEE Trans. Microwave Theory Tech., vol. 49, pp. 1593-1598, Sept. 2001.

Peter de Maagt (S'88-M'88-SM'02) was born in Pauluspolder, The Netherlands, in 1964. He received the M.Sc. and Ph.D. degrees from Eindhoven University of Technology, Eindhoven, The Netherlands, in 1988 and 1992, respectively, both in electrical engineering.

He is currently with the European Space Research and Technology Centre (ESTEC), European Space Agency, Noordwijk, The Netherlands. His research interests are in the area of millimeter and submillimeter-wave reflector and planar integrated antennas, quasioptics, photonic bandgap antennas, and millimeter- and submillimeter-wave components.

Dr. de Maagt was a co-recipient of the H.A. Wheeler award of the IEEE Antennas and Propagation Society for the best applications paper of the year 2001. He was granted a European Space Agency award for innovation in 2002.

Ramón Gonzalo (S'95-M'99) was born on July 15, 1972, in Logroño, La Rioja. He received the M.Sc. degree in "Ingeniero de Telecomunicación" with honors and the Ph.D. degree from the Public University of Navarra (UPNa), Spain, in 1995 and 1999, respectively.

Since October 1995, he has been a Research Assistant in the Microwave Section, Electrical and Electronic Department, UPNa. His current area of research is in the field of Photonic Band Structures with emphasis on space antenna applications, design of waveguide transmission lines and corrugated horn antennas.

Mr. Gonzalo received a grant from the Spanish Government to work at the European Space Research and Technology Center (ESTEC), ESA, The Netherlands in September 1997. 
Yiannis C. Vardaxoglou (M'88) received the B.Sc. degree in mathematics (mathematical physics) and the Ph.D. degree from the University of Kent, Canterbury, U.K., in 1981 and 1985, respectively.

He was appointed a Lecturer in Communications in the Department of Electronic and Electrical Engineering at Loughborough University of Technology, Loughborough, U.K., in January 1988, and he was promoted to the position of Senior Lecturer in January 1992. In 1998, he was appointed Professor of Wireless Communications. He established the Antennas and Microwaves Research at Loughborough University and heads the Centre for Mobile Communications Research (CMCR). He has been active in the area of electromagnetic modeling and applications of FSS. His current research interests include wireless communication networks, array antennas, FSS, radomes, leaky-wave resonant antennas, optical control of microwaves and devices, periodic surfaces and PBG materials, and mobile telephone antennas. His contribution to the CMCR lies in the analysis and design of small bifilar and quadrifilar antennas for mobile telephony. He has served as a consultant to various industries in the U.K. and abroad. He has published over 100 refereed journals and conference proceedings papers and has written a research monograph on FSS.
Jean-Marc Baracco was born in Antibes, France, in 1963. He received the M.Sc. and Ph.D. degrees from the University of Nice Sophia-Antipolis, Nice, France, in 1989 and 1993, respectively, both in electrical engineering, in cooperation with the France Télécom Research Centre of La Turbie, France.

After graduation, he was granted a research fellowship by the European Space Agency Research and Technology Centre (ESTEC), Noordwijk, The Netherlands, where he developed printed array antennas. In 1995, he joined Saab Ericsson Space, Gothenburg, Sweden, where he primarily worked on array antennas for earth observation missions, and helix antennas for TTC. In 2000, he started the company MARDEL, Vence, France, where he works on wire antennas, helix antennas, printed antennas, array antennas, electromagnetic bandgap antennas and passive microwave components. He is coauthor of several patents in the antenna field. 